\title{
Selección de poemas de François Villon
}

\section{Beatriz Martínez-Ojeda}

F rançois Villon, poeta parisino de finales de la Edad Media y principios del Renacimiento francés, ha pasado a la historia de la literatura francesa como el primer 'poeta maldito', tanto por el drama de sus vivencias personales - fue condenado a la horca en dos ocasiones - como por el patetismo, crudeza y socarronería de sus composiciones poéticas.

Su obra principal, Le Testament (1461), ha sido ampliamente traducida a multitud de lenguas, siendo objeto de un mayor número de versiones las baladas que en ella se insertan, las cuales constituyen la composición lírica por excelencia del bardo, cuyo nombre se debe a que originalmente fueron concebidas para ser declamadas en voz alta con acompañamiento musical como si de canciones se tratara - recordemos la arraigada tradición en la Europa medieval de entonar las creaciones poéticas por medio de la voz de juglares y trovadores-. En ellas prima la enseñanza moral de carácter generalmente burlón expresada por medio del estribillo final o envoi. Algunas de las baladas que más han trascendido a lo largo de los años no se encuentran, sin embargo, en su obra más representativa, sino en el poemario denominado Poésies diverses, compuesto por dieciséis poemas, mayoritariamente baladas, entre las que se incluyen algunas de las traducidas en nuestra selección - a excepción de "Ballade des dames du temps jadis" y "Ballade des femmes de Paris", que se sitúan entre las más célebres de Le Testament-.

Actualmente, Villon continúa generando literatura en torno a su vida y a su obra, literatura en la que la traducción ocupa un lugar preponderante, pese a que en este intento por perpetuar las composiciones del poeta y de convertirlo en un autor atemporal prime más el embellecimiento del texto resultante mediante la rima que la reproducción fiel de sus mensajes. 
Tant gratte chèvre que mal gît, Tant va le pot à l'eau qu'il brise, Tant chauffe-on le fer qu'il rougit, Tant le maille-on qu'il se débrise, Tant vaut l'homme comme on le prise, Tant s'élogne-il qu'il n'en souvient, Tant mauvais est qu'on le déprise, Tant crie-l'on Noël qu'il vient.

Tant parle-on qu'on se contredit, Tant vaut bon bruit que grâce acquise, Tant promet-on qu'on s'en dédit, Tant prie-on que chose est acquise, Tant plus est chère et plus est quise, Tant la quiert-on qu'on y parvient, Tant plus commune et moins requise, Tant crie-l'on Noël qu'il vient.

Tant aime-on chien qu'on le nourrit, Tant court chanson qu'elle est apprise, Tant garde-on fruit qu'il se pourrit, Tant bat-on place qu'elle est prise, Tant tarde-on que faut l'entreprise, Tant se hâte-on que mal advient, Tant embrasse-on que chet la prise, Tant crie-l'on Noël qu'il vient.

Tant raille-on que plus on n'en rit, Tant dépent-on qu'on n'a chemise, Tant est-on franc que tout y frit, Tant vaut "Tiens !" que chose promise, Tant aime-on Dieu qu'on fuit l'Eglise, Tant donne-on qu'emprunter convient, Tant tourne vent qu'il chet en bise, Tant crie-l'on Noël qu'il vient.

Prince, tant vit fol qu'il s'avise, Tant va-il qu'après il revient, Tant le mate-on qu'il se ravise, Tant crie-l'on Noël qu'il vient.
Tanto se rasca la cabra, que se daña; tanto va el cántaro a la fuente, que se rompe; tanto se calienta el hierro, que se pone rojo, tanto se golpea, que se parte; tanto vale el hombre, cuanto se le aprecia, tanto se aleja, que lo olvidan, tan malo es, que se le desprecia, tanto se invoca la Navidad, que al fin llega.

Tanto habla uno, que se contradice; tanto vale buena fama como gracia obtenida; tanto promete uno, que se desdice; tanto se suplica, que las cosas se consiguen, tanto más querida, cuanto más buscada, tanto se busca, que se encuentra, tanto más frecuente, cuanto menos deseada, tanto se invoca la Navidad, que al fin llega.

Tanto se quiere al perro, que se le da de comer; tanto corre la canción, que al fin se aprende; tanto se guarda la fruta, que se pudre; tanto se hostiga una plaza, que es conquistada; tanto se tarda, que fracasa la empresa; tanto se precipita, que mal acaba; tanto se aprieta, que cae la presa, tanto se invoca la Navidad, que al fin llega.

Tanto se bromea, que ya no da risa; tanto se gasta, que no se tiene camisa; tanto es uno generoso, que todo se lo gasta; tanto vale "toma", como cosa prometida; tanto se ama a Dios, que se huye de la Iglesia; tanto se da, que conviene pedir prestado; tanto sopla el viento, que se vuelve cierzo, tanto se invoca la Navidad, que al fin llega.

Príncipe, tanto vive el loco, que sana, tanto va, que al fin vuelve, tanto se le golpea, que muda de parecer, tanto se invoca la Navidad, que al fin llega. 
Dites-moi où, n'en quel pays,

Est Flora la belle Romaine,

Archipiades, ne Thaïs,

Qui fut sa cousine germaine,

Echo, parlant quant bruit on mène

Dessus rivière ou sur étang,

Qui beauté eut trop plus qu'humaine?

Mais où sont les neiges d'antan?

Où est la très sage Héloïs,

Pour qui fut châtré et puis moine

Pierre Esbaillart à Saint-Denis ?

Pour son amour eut cette essoine.

Semblablement, où est la roine

Qui commanda que Buridan

Fût jeté en un sac en Seine?

Mais où sont les neiges d'antan?

La roine Blanche comme un lis

Qui chantait à voix de sirène,

Berthe au grand pied, Bietrix, Aliz,

Haramburgis qui tint le Maine,

Et Jeanne, la bonne Lorraine

Qu'Anglais brûlèrent à Rouen ;

Où sont-ils, où, Vierge souvraine?

Mais où sont les neiges d'antan?

Prince, n'enquerrez de semaine

où elles sont, ni de cet an,

Que ce refrain ne vous remaine :

Mais où sont les neiges d'antan?
Decidme dónde, en qué país

se halla Flora la bella romana,

Archipiada y Thaís,

que fue su prima hermana;

Eco, que contesta al ruido

sobre riberas o estanques,

¿quién tuvo belleza más que humana?

¿Mas, do son las nieves de antaño?

¿Dónde la culta Eloísa,

por quien fue castrado y monje

Abelardo en San Denís?

Por su amor pasó esta pena.

De igual modo, ¿do la reina

que ordenó que Buridán

al Sena en saco arrojaran?

¿Mas, do son las nieves de antaño?

La reina Blanca cual lis,

que cual sirena cantaba;

Berta la del gran pie, Beatriz, Alís;

Arembour del Maine dueña

y Juana, la lorenesa,

llevada en Rouen a la hoguera;

¿do están Virgen soberana?

¿Mas, do son las nieves de antaño?

No insistáis dónde están, Príncipe,

ni este año, ni esta semana,

que os remito a este refrán:

¿mas, do las nieves de antaño? 
Quoiqu'on tient belles langagères

Florentines, Vénitiennes,

Assez pour être messagères,

Et mêmement les anciennes,

Mais soient Lombardes, Romaines.

Genevoises, à mes périls,

Pimontoises, savoisiennes,

Il n'est bon bec que de Paris.

De beau parler tiennent chaières,

Ce dit-on, les Napolitaines,

Et sont très bonnes cacquetières

Allemandes et Prussiennes;

Soient Grecques, Egyptiennes,

De Hongrie ou d'autres pays,

Espagnoles ou Catelennes,

Il n'est bon bec que de Paris.

Brettes, Suisses n'y savent guères,

Gasconnes, n'aussi Toulousaines:

De Petit Pont deux harengères

Les concluront, et les Lorraines,

Angloises et Calaisiennes,

(Ai-je beaucoup de lieux compris?)

Picardes de Valenciennes;

Il n'est bon bec que de Paris.

Prince, aux dames parisiennes

De bien parler donnez le prix;

Quoi que l'on die d'Italiennes,

Il n'est bon bec que de Paris.
Aunque de gran elocuencia sean

las florentinas y venecianas, además de buenas mensajeras incluso cuando llegan a ancianas; pero sean lombardas, romanas, genovesas, esto os lo aseguro, piamontesas y hasta saboyanas, no hay pico como el de París.

Con su hablar cátedra sientan al parecer las napolitanas, y también son diestras parlanchinas alemanas y prusianas. Ya sean griegas, egipcias, de Hungría o de cualquier otro país, españolas o catalanas, no hay pico como el de París.

$\mathrm{Ni}$ bretonas ni suizas las superan tampoco gasconas ni tolosanas, dos pescaderas del Petit Pont, las callarán. Y Lorenesas, inglesas y también calesianas, — ime dejo en el tintero a alguna? Picardas de Valenciennes.

No hay pico como el de París.

Príncipe, a las damas parisinas dad el premio al buen hablar, aunque digan de italianas, no hay pico como el de París. 
RoNDEL VIII

Adieu vous dy la lerme à l'œil;

Adieu, ma très gente mignonne,

Adieu, sur toutes la plus bonne,

Adieu vous dy, qui m'est grand dueil.

Adieu, adieu, m'amour, mon vueil;

Mon povre cueur vous laisse et donne.

Adieu vous dy la lerme à l'œil.

Adieu, par qui du mal recueil

Mille fois plus que mot ne sonne;

Adieu, du monde la personne

Dont plus me loue et plus me dueil.

Adieu vous dy la lerme à l'œil.
RoNDEL VIII

Adiós, lágrimas en mis ojos

adiós, mi más gentil señora,

adiós a la mejor de todas,

adiós os digo, a mi mayor pena.

Adiós, adiós, mi amor, mi anhelo

mi pobre corazón de vos se aleja,

adiós os digo con lágrimas en mis ojos.

Adiós, a aquella por quien mal recogí

mil veces más de lo que se puede decir; adiós, del mundo a la persona

por quien más me glorío y más sufro.

Adiós os digo con lágrimas en mis ojos.

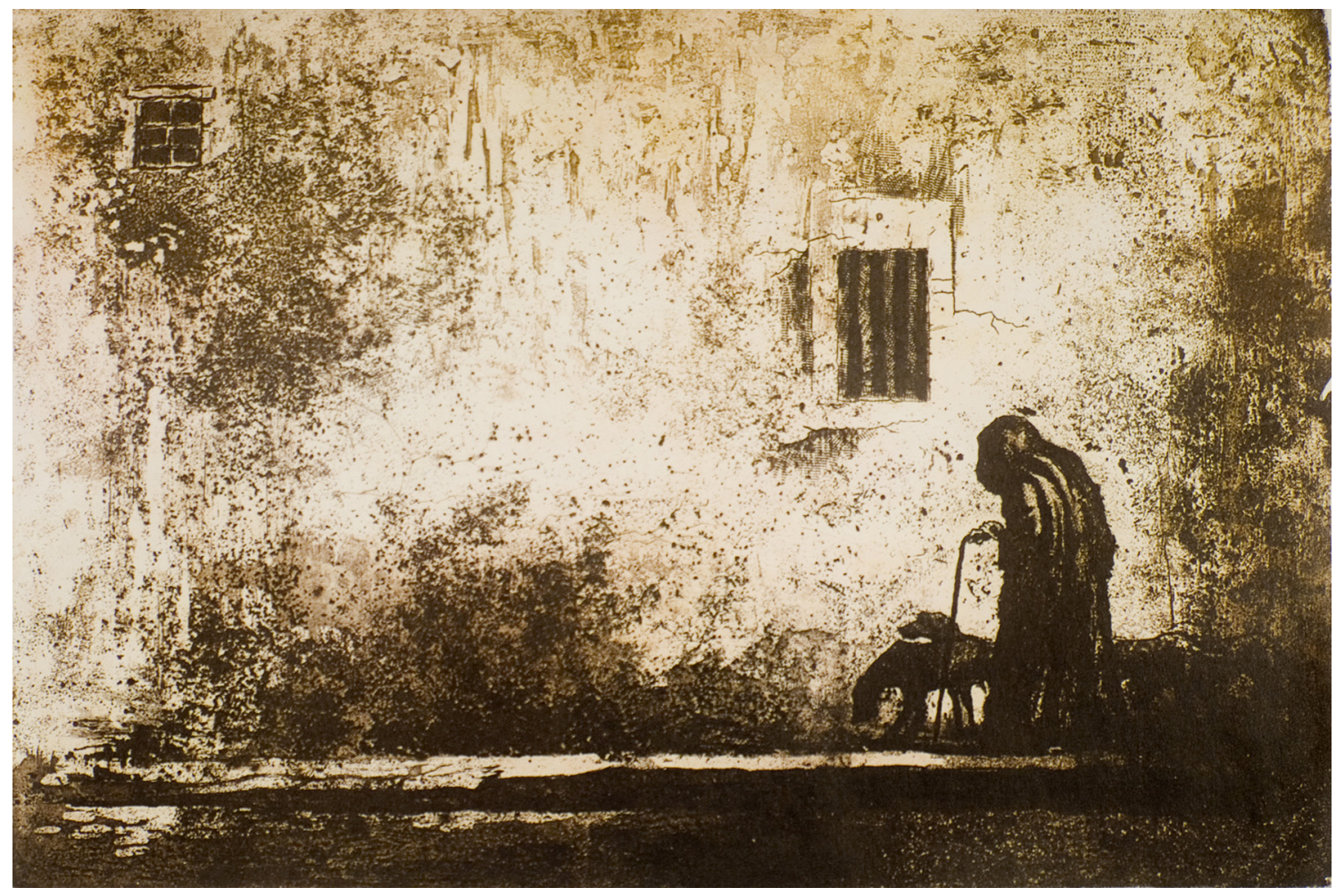

Soledad (1965). Técnica mixta sobre metal: Jesús Gallardo. Prohibida su reproducción en obras derivadas. 
Je meurs de seuf auprès de la fontaine, Chaud comme feu, et tremble dent à dent; En mon pays suis en terre lointaine; Lez un brasier frissonne tout ardent; Nu comme un ver, vêtu en président, Je ris en pleurs et attends sans espoir; Confort reprends en triste désespoir; Je m'éjouis et n'ai plaisir aucun; Puissant je suis sans force et sans pouvoir, Bien recueilli, débouté de chacun.

Rien ne m'est sûr que la chose incertaine; Obscur, fors ce qui est tout évident; Doute ne fais, fors en chose certaine; Science tiens à soudain accident; Je gagne tout et demeure perdant; Au point du jour dis: "Dieu vous doint bon [soir!"

Gisant envers, j'ai grand paour de choir; J'ai bien de quoi et si n'en ai pas un; Echoite attends et d'homme ne suis hoir, Bien recueilli, débouté de chacun.

De rien n'ai soin, si mets toute m'atayne D'acquérir biens et n'y suis prétendant; Qui mieux me dit, c'est cil qui plus m'ataine, Et qui plus vrai, lors plus me va bourdant; Mon ami est, qui me fait entendant D'un cygne blanc que c'est un corbeau noir; Et qui me nuit, crois qu'il m'aide à pourvoir; Bourde, verté, aujourd'hui m'est tout un; Je retiens tout, rien ne sait concevoir, Bien recueilli, débouté de chacun.

Prince clément, or vous plaise savoir Que j'entends mout et n'ai sens ne savoir: Partial suis, à toutes lois commun. Que sais-je plus? Quoi? Les gages ravoir, Bien recueilli, débouté de chacun.
De sed me muero cerca de la fuente, cual fuego ardiente tiemblan mis dientes; en mi país me siento en tierra ajena; de calor tirito junto a una hoguera; desnudo cual lombriz, visto de presidente, río entre lágrimas y sin fe espero; consuelo hallo en triste desespero; me regocijo sin placer alguno; poderoso soy sin poder ni fuerza, bien me acogen, mas todos me rechazan.

Nada me es más cierto que cosa incierta; ni me es más confuso que lo evidente; de nada dudo salvo de lo cierto; la ciencia es sólo casual accidente; perdedor me siento aun ganando todo; al alba digo: iBuenas noches nos dé Dios!;

en el suelo, tengo miedo de caer; tengo posibles y no tengo un ochavo; espero herencia sin ser heredero, bien me acogen, mas todos me rechazan.

Nada me preocupa, en todo me afano, como en adquirir bienes que ni quiero; el que mejor me habla es quien más me ofende y el más sincero es aquel que más miente; mi mejor amigo es quien me hace creer que un cisne blanco es un oscuro cuervo; y quien más me daña yo creo que ayuda; ardid, verdad, iguales se me antojan; todo retengo, no logro inventar; bien me acogen, mas todos me rechazan.

Príncipe indulgente, tal vez debáis saber que comprendo todo sin lógica ni ciencia, siendo parcial a la ley me atengo. ¿Qué sé además? ¿Qué? Mis bienes recobrar, bien me acogen, mas todos me rechazan. 
L'ÉptTAphe de Villon ou Ballade des pendus

Frères humains, qui après nous vivez, N'ayez les cœurs contre nous endurcis, Car, si pitié de nous pauvres avez, Dieu en aura plus tôt de vous mercis. Vous nous voyez ci attachés, cinq, six: Quant à la chair, que trop avons nourrie, Elle est piéça dévorée et pourrie, Et nous, les os, devenons cendre et poudre. De notre mal personne ne s'en rie ; Mais priez Dieu que tous nous veuille absoudre!

Se frères vous clamons, pas n'en devez Avoir dédain, quoique fûmes occis Par justice. Toutefois, vous savez Que tous hommes n'ont pas bon sens rassis. Excusez-nous, puisque sommes transis, Envers le fils de la Vierge Marie, Que sa grâce ne soit pour nous tarie,

Nous préservant de l'infernale foudre. Nous sommes morts, âme ne nous harie, Mais priez Dieu que tous nous veuille absoudre!

La pluie nous a débués et lavés, Et le soleil desséchés et noircis.

Pies, corbeaux nous ont les yeux cavés, Et arraché la barbe et les sourcils. Jamais nul temps nous ne sommes assis

Puis çà, puis là, comme le vent varie, A son plaisir sans cesser nous charrie, Plus becquetés d'oiseaux que dés à coudre.

Ne soyez donc de notre confrérie; Mais priez Dieu que tous nous veuille absoudre!

Prince Jésus, qui sur tous a maistrie, Garde qu'Enfer n'ait de nous seigneurie:

A lui n'ayons que faire ne que soudre. Hommes, ici n'a point de moquerie; Mais priez Dieu que tous nous veuille absoudre

\section{EPITAFIO de VILLON O BALAdA dE LOS AHORCAdos}

Hermanos terrenales, que nos sobreviviréis, no os mostréis con nosotros duros de corazón, pues si mostráis piedad por nuestra desventura, Dios clemencia mostrará con vosotros.

Cinco o seis de nosotros veis colgados aquí: ved cómo nuestra carne, que tanto alimentamos, desde hace tiempo corroída está y podrida; el resto, nuestros huesos, serán polvo y cenizas. iQue de nuestra desgracia no se regodee nadie, sino rogad a Dios para que nos absuelva!

Si hermanos os llamamos, no por ello debéis mirarnos con desdén, aunque fuimos ahorcados por sentencia. No obstante, vosotros bien sabéis que no todos los hombres tienen serena el alma; el perdón concedednos, ya que nos dirigimos hacia el hijo de la Virgen María, para que así su gracia no se extinga en [nosotros, y pueda preservarnos de la luz infernal. Muertos estamos, que nadie nos torture, isino rogad a Dios para que nos absuelva!

La lluvia ha limpiado y lavado, y el sol nos ha secado y luego ennegrecido: las urracas y cuervos nos sacaron los ojos, arrancándonos la barba y las cejas.

Nunca, un solo momento, sentados

[descansamos:

fuimos de aquí a allá según soplara el viento que a su gusto y antojo, nos balancea incesante, picoteados por pájaros más que un dedal de

[sastre.

iNo queráis ser, por tanto, de nuestra cofradía, sino rogad a Dios para que nos absuelva!

Príncipe Jesucristo, que puedes sobre todo, cuida de que el Infierno no pueda sobre

[nosotros: que trato con él no haya ni salde cuenta alguna. iHombres, aquí no toméis nada en broma, sino rogad a Dios para que nos absuelva! 
Rencontré soit de bêtes feu jetant

Que Jason vit, quérant la Toison d'or;

Ou transmué d'homme en bête sept ans

Ainsi que fut Nabugodonosor;

Ou perte il ait et guerre aussi vilaine

Que les Troyens pour la prise d'Hélène;

Ou avalé soit avec Tantalus

Et Proserpine aux infernaux palus;

Ou plus que Job soit en grieve souffrance,

Tenant prison en la tour Dedalus,

Qui mal voudroit au royaume de France!

Quatre mois soit en un vivier chantant,

La tête au fond, ainsi que le butor;

Ou au grand Turc vendu deniers comptants,

Pour être mis au harnais comme un tor;

Ou trente ans soit, comme la Magdelaine,

Sans drap vêtir de linge ne de laine;

Ou soit noyé comme fut Narcissus,

Ou aux cheveux, comme Absalon, pendus,

Ou, comme fut Judas, par Despérance;

Ou puist périr comme Simon Magus,

Qui mal voudroit au royaume de France!

D'Octovien puist revenir le temps:

C'est qu'on lui coule au ventre son trésor;

Ou qu'il soit mis entre meules flottant

En un moulin, comme fut saint Victor;

Ou transglouti en la mer, sans haleine,

Pis que Jonas ou corps de la baleine;

Ou soit banni de la clarté Phébus,

Des biens Juno et du soulas Vénus,

Et du dieu Mars soit pugni à outrance,

Ainsi que fut roi Sardanapalus,

Qui mal voudroit au royaume de France!

Prince, porté soit des serfs Eolus

En la forêt où domine Glaucus,

Ou privé soit de paix et d'espérance :

Car digne n'est de posséder vertus,

Qui mal voudroit au royaume de France!
iHallado sea por fieras salvajes

como Jasón buscando el vellocino;

o transformado en bestia por siete años,

como lo fue Nabucodonosor;

o sufra pérdida o guerra tan cruenta

como la de Troya a causa de Elena;

o termine sumido junto a Tántalo

y Proserpina en el foso infernal;

o más sufrimiento que Job padezca,

o prendido como reo en la torre de Dédalo

aquel que el mal desee al reino de Francia!

iCuatro meses pase en pozo cantando

cabeza abajo como el alcaraván;

sea entregado y vendido al Gran Turco,

y le coloquen arnés como al buey;

treinta años como la Magdalena

pase sin vestido de lino o lana;

se ahogue como le ocurrió a Narciso;

o de los cabellos colgado como Absalón;

o como Judas, por su desesperanza,

o perezca como el Mago Simón,

aquel que el mal desee al reino de Francia!

iQue vuelvan los tiempos de Octaviano, para que así le hagan tragar oro; o sea colocado entre las muelas de un molino, como lo fue San Víctor; o lo engulla el mar sin aliento peor que Jonás se halle en la ballena; desterrado sea del fulgor de Febo, de los bienes de Juno y el solaz de Venus; y por Marte sea castigado a ultranza, tal y como lo fue el rey Sardanápalo, aquel que el mal desee al reino de Francia!

iPríncipe, lo rapten siervos de Eolo, en la floresta donde reina Glauco; o privado sea de paz y esperanza: pues no es digno de poseer virtudes aquel que el mal desee al reino de Francia! 


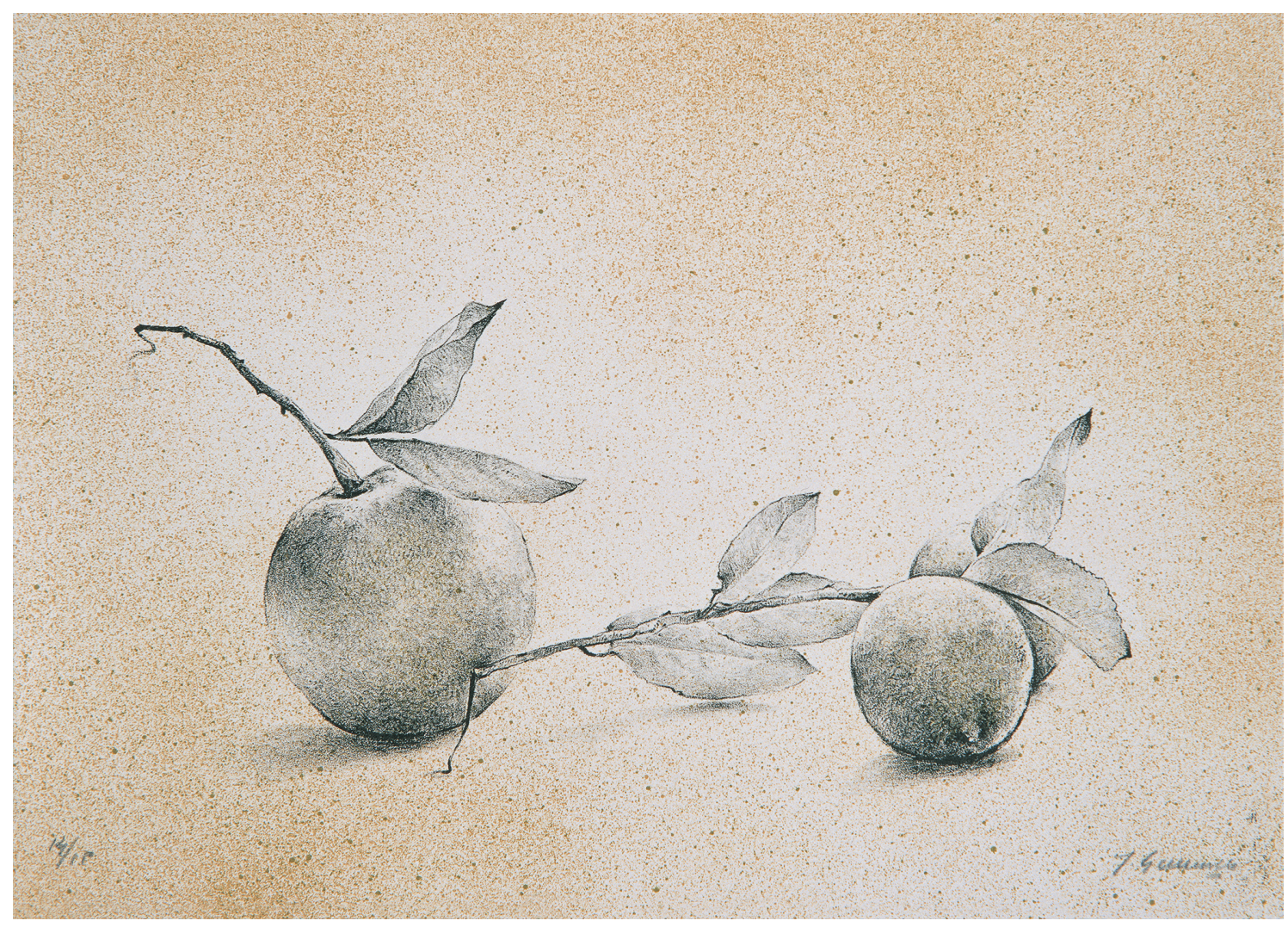

Naranjas (1980). Litografía: Jesús Gallardo.

Prohibida su reproducción en obras derivadas.

Beatriz Martínez Ojeda. Doctora en Traducción e Interpretación por la Universidad de Córdoba, España. Catedrática de la Facultad de Filosofía y Letras de la misma institución. Sus intereses académicos versan sobre la traducción literaria, la traducción poética (francés/inglés-español), la literatura comparada y los estudios de género y traducción. Entre sus publicaciones más recientes se encuentran: "La traducción poética: aproximación a la traducción del ritmo en la poesía de François Villon" (Çédille. Revista de Estudios Franceses, núm. 14); "El Traité de la uraie cause des maladies et manière de les guérir (1776) de Jean Gaspard d'Ailhaud: análisis y traducción" (Educación Médica, vol. 19, núm. S2, ); "Claire d'Albe (1799) de Mme Cottin y la traducción al español de 1822" (Epos. Revista de Filología, núm. XXXIII.

(D) $0000-0002-6812-4646$

Recibido: 28 de enero de 2019

Aprobado: 3 de junio de 2019 